\title{
Effect of Frequency on Eddy Losses of Transformers
}

\author{
Ylldırım Özüpak \\ Dicle University Silvan Vocational School, Electrical and Energy Department, Diyarbakır, Turkey \\ E-mail address: yildirim.ozupak@dicle.edu.tr \\ ORCID numbers of author: \\ 0000-0001-8461-8702
}

Received date: 12.02 .2021

Accepted date: 08.03.2021

\begin{abstract}
Transformer is a vital component of electrical power systems for transmission and distribution. Robust design to increase the efficiency of a transformer is one of the main factors in transformer manufacturing. The efficiency of a practical transformer is limited by the losses caused by design and manufacturing defects. Losses in transformers can be divided into idle losses and losses under load. Eddy current loss is obtained from the idle losses of the transformer. In this paper, the effect of eddy effect causing HV energy loss at high magnetization frequencies was investigated. ANSYS@Maxwell software based on the Finite Element Method was used to analyze the eddy current loss in a T-connected, 3-leg and 3-phase distribution transformer of 15 MVA. The losses are obtained from no-load tests by changing the operating frequency of the transformer. Depending on the frequency value in the range of 50-60 Hz, the change in eddy current loss has been observed while the transformer winding is excitation at $1.74 \mathrm{~T}$ magnetic flux density. It has been observed that increasing the frequency causes an increase in the no load loss in the 3-phase transformer.
\end{abstract}

Keywords: Transformer, FEM, Frequency, Magnetic field, Eddy current loss.

\section{Introduction}

Calculating the parameters of power transformers, designing, modeling and realizing lifelike simulations of these transformers has always been a challenge for designers. These transformers are the most expensive item of energy transmission and distribution facilities. For this reason, it has always been important for designers to predict the correct operation of the transformer and to know the possible failures that may occur. They performed the study and analysis of high frequency models of power transformers for the analysis of the transient interaction between power systems and transformers [1]. It realizes the identification of different internal faults that cause power cuts in transformers with an algorithm and transformer model [2]. In recent years, with the development of computer software programs, different nonlinear core materials used in transformers core and simulation programs based on Finite Element Method (FEM) have been used intensively to model the permanent magnetization of these materials [3]. ANSYS @ Maxwell based on FEM was used to calculate the parameters of the model transformer in discharges occurring in the windings of transformers [4]. Mains frequency controlled or uncontrolled rectifiers used in power electronics draw currents containing harmonic components from the electric grid. The loss of 
transformers in the no-load state consists of eddy and hysteresis losses. [5]. The effect of eddy loss on transformer loss can be calculated as:

$$
P_{e}=k B_{\max }^{2} f^{2}
$$
K: constant
B: maximum flux density
F: frequency

The losses occurring in the transformer's magnetic core reach high values at high frequencies [6]. It shows that by using ferromagnetic material in a transformer core model, the core loss increases with increasing frequency [7].

Eddy currents become negligible at very low magnetization frequency. This allows a method is as shown in Fig. 1. A summary of the core loss mechanism is given in Fig. 2.

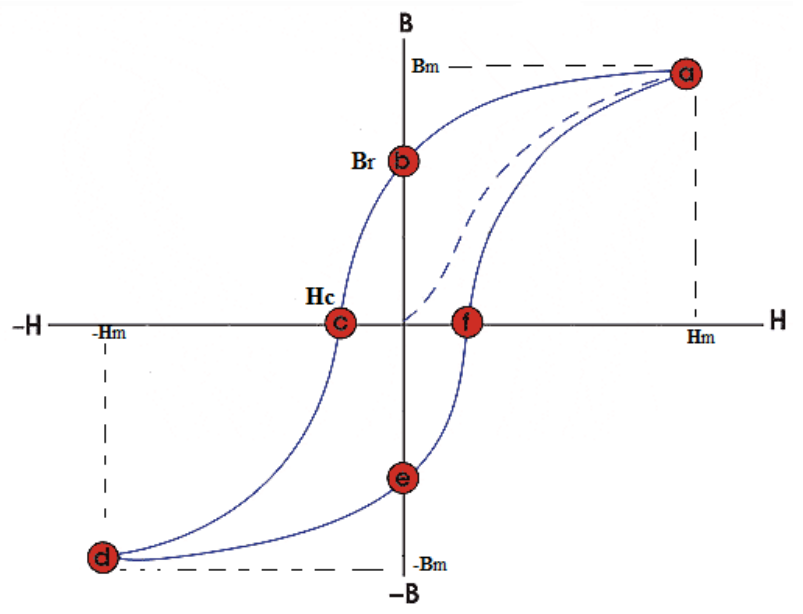

Fig. 1. Hysteresis curve of magnetic materials

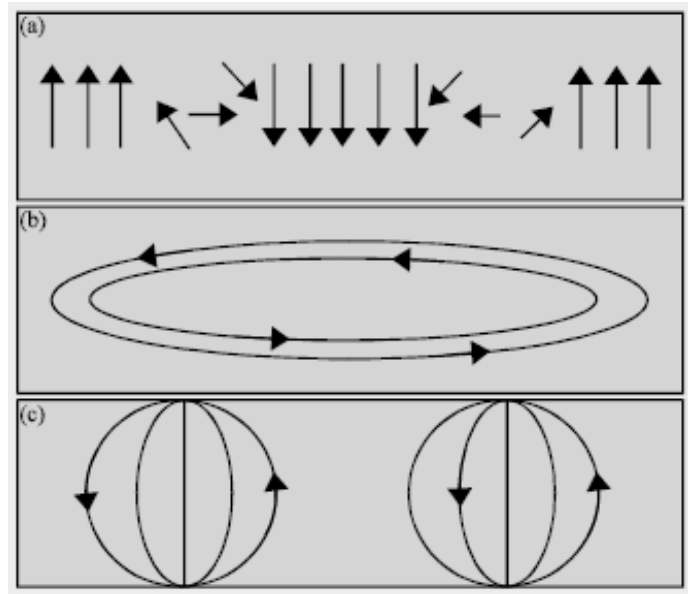

Fig. 2. Core loss summary. 
The power loss of no load transformer may be written as [6]:

$$
P_{T}=P_{h}+P_{e}+P_{a}
$$

Eddy currents in transformer cores can be minimized. This reduces the conventional eddy current losses that are highly based on core material thickness $[8,9]$.

\section{Material and Method}

The main component core consists of a three-legged three-phase 15 MVA transformer core with a T-joint shear angle. The characteristics of the transformer are given in Table 1.

Table 1. Properties of Transformer

\begin{tabular}{cc}
\hline Parameter & Value \\
Rated Power & $15 . \mathrm{MVA}$ \\
HV & $33.000 \mathrm{~V}$ \\
LV & $11.000 \mathrm{~V}$ \\
Frequency & $50 \mathrm{~Hz}$ \\
HV turn number & 665 \\
LV turn number & 128 \\
Material & $\mathrm{M} 125-027 \mathrm{~S}$ \\
Material thickness & $0.3 \mathrm{~mm}$ \\
Conductivity & $5000000 \mathrm{~S} / \mathrm{m}$ \\
Stacking factor & 0.95 \\
\hline
\end{tabular}

In core type transformer, both primary and secondary windings are placed on side limbs. This type of transformer has two magnetic circuits. Fig. 3 shows the prototype of the core type transformer designed.

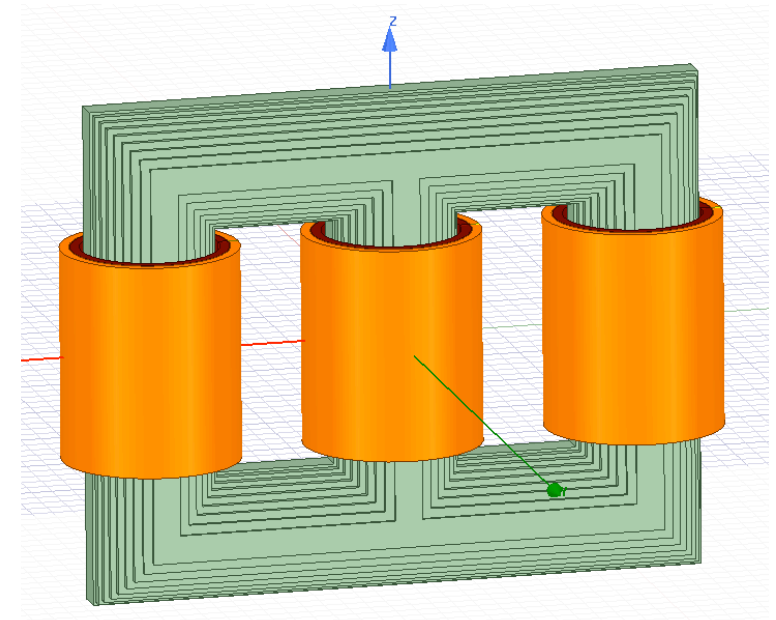

Fig. 3. Core type three-phase transformer. 
In the transformer model, the boundary conditions are defined on the external geometry and properties of all materials. The magnetic core is characterized by thin laminations such as the B-H curve of magnetization given in Fig. 4 [1-2].

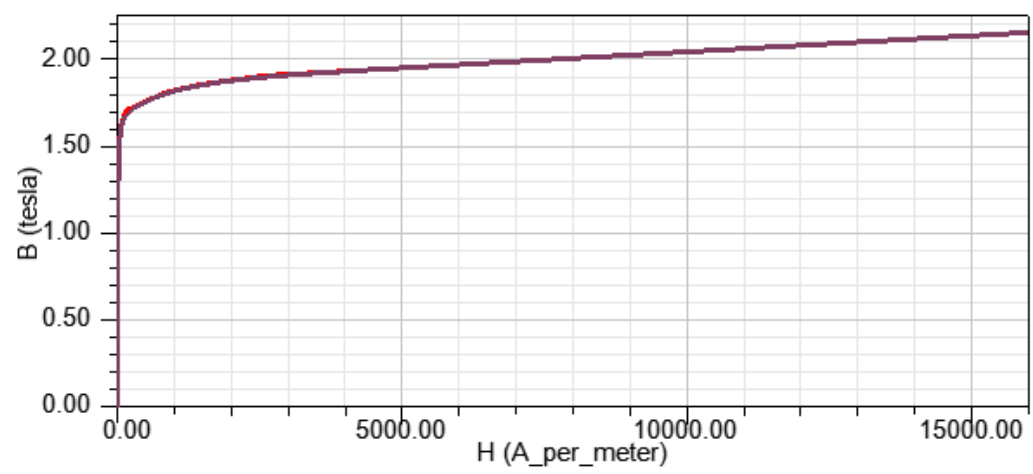

Fig. 4. B-H curve of core material

In order to eliminate sudden currents and shorten the simulation time, exponential excitation is given as given in Fig. 5 .

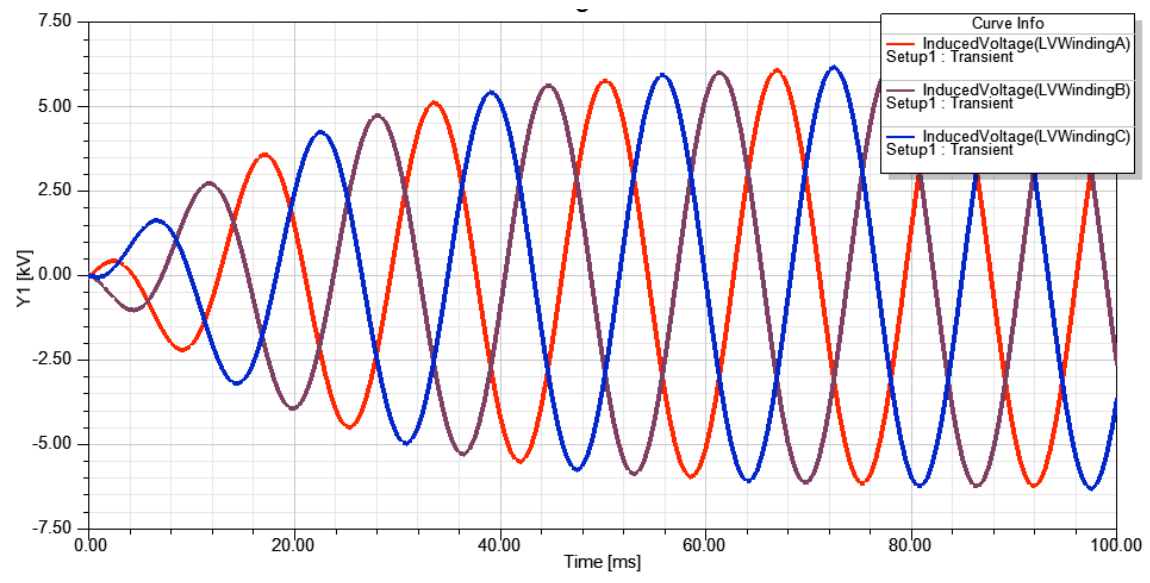

Fig. 5. Transformer excitation voltage curve

In order to analyze the designed model, the entire model is divided into many elements, usually triangles. The mesh (mesh) of the model created with finite elements is presented in Fig. 6.

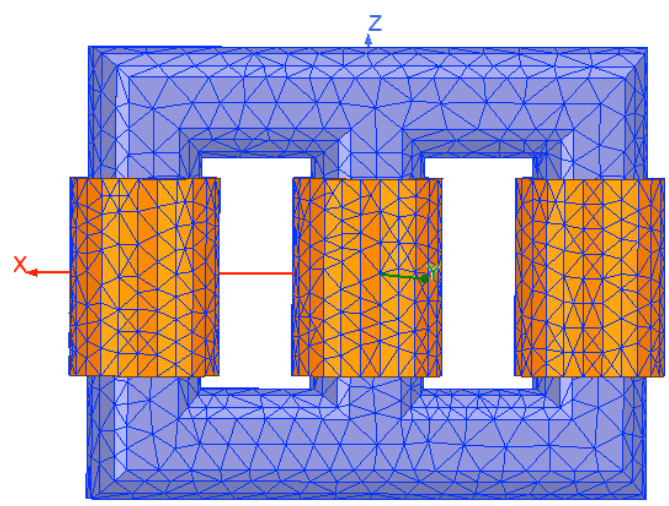

Fig. 6. Mesh of transformer. 
Testing has been done using the no-load test test. Each winding is also designed so that the stepped length of the three phase core can be varied.

\section{Analysis and Results}

The magnetic flux distribution of the designed transformer model at $50 \mathrm{~Hz}$ frequency and depending on the variable magnetic field is given in Figure 7.

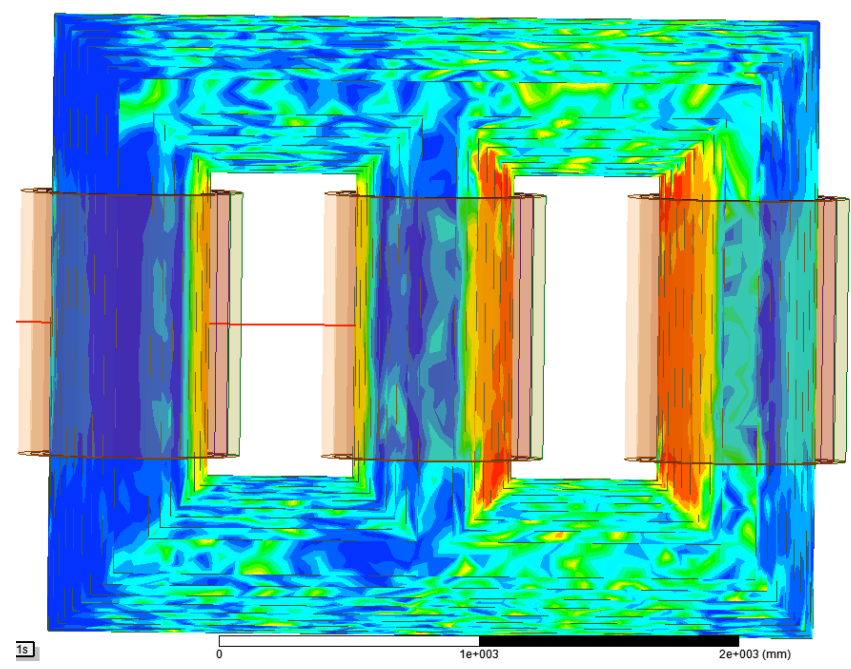

Fig. 7. Magnetic flux distribution.

The variation of the eddy current loss in three phase cores is presented in Figure 8. As a result of this research, it was seen that the core loss was $12.41 \mathrm{~kW}$. The loss in this study is the classical eddy current. Table 2 shows the eddy current loss variation obtained from the simulation.

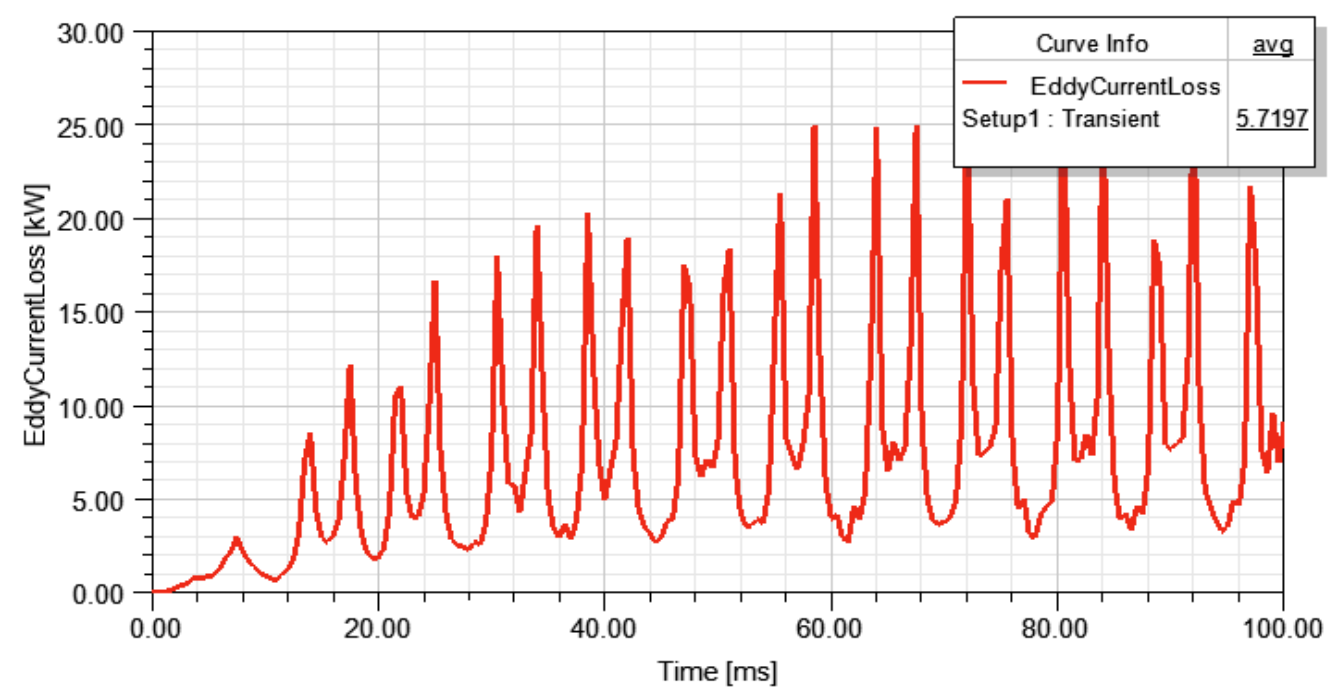

Fig. 8. Eddy current loss at $50 \mathrm{~Hz}$ frequency 
Table 2. Variation of eddy current loss with frequency

\begin{tabular}{cc}
\hline Frequency $(\mathrm{Hz})$ & Eddy Current Loss $(\mathrm{kW})$ \\
50 & 5.748 \\
52 & 5.931 \\
54 & 6.121 \\
56 & 6.218 \\
58 & 6.355 \\
60 & 6.421 \\
\hline
\end{tabular}

In cases where the frequency increased, the eddy current loss increased. It can be clearly stated that there is much about eddy current losses in the literature. When the flow, flux density and frequency value of the flux in the junctions increase, due to the movement of the flux, there is an air gap between the joints, so the flux adhering to the joint and this will allow the magnetic flux to flow to the other electrical steel lamine. Flux will be circulated in the field as shown. As a result, it has been seen how eddy current losses increase depending on the increase in frequency.

\section{Conclusions}

In this paper, from the results of the model analyzed at $50 \mathrm{~Hz}$ frequency, it was seen that the lowest power loss of the transformer core, ie eddy current losses, has a significant effect on the total core losses of the idle 3-phase transformer. The increase in frequency has caused an increase in transformer core losses. The eddy current losses on the core also varied depending on the change of magnetic flux. As a result, it has been seen how eddy current losses increase depending on the increase in frequency.

\section{Acknowledgments}

This study was supported by Inonu University Scientific Research Projects Coordination Unit. Project Number: FBA-2017-639.

\section{References}

[1] Özüpak, Y., Mamiş, M.S., Realization of electromagnetic flux and thermal analyses of transformers by finite element method, IEEJ Transactions on Electrical and Electronic Engineering, 14(10), 1478-1484, 2019.

[2] Morched, A., Marti, L., Ottevangers J., A high frequency transformer model for the EMTP, IEEE Transactions on Power Delivery, 8(3), 1615-1626, 1993.

[3] Özüpak, Y., Mamiş, M.S., Teke, İ.H., Electromagnetic field and total loss analysis of transformers by finite element method, International Journal of Engineering And Computer Science, 8(1), 24451-24460, 2019.

[4] Özüpak, Y., Mamiş, M.S., Realization of electromagnetic flux and thermal analyses of transformers by finite element method, IEEJ Transactions on Electrical and Electronic Engineering, 14(10), 1478-1484, 2019.

[5] Subedi, D., Lightning induced over-voltages in power transformer and voltage spikes in connected load, Master Thesis, Aalto University, Helsinki, Finland, 2017.

[6] Shirvani, A., Malekian, K., Schmidt, U., Schufft, W., A New Power transformer Model Over Wide Frequency range for EMTP, 45th International Universities Power Engineering Conference UPEC2010, 1-6, 2010. 
[7] Sabiha, N.A., Lightning-induced overvoltages in mediumvoltage distribution systems and customer experienced voltage spikes, $\mathrm{PhD}$ Thesis, Aalto University, Helsinki, Finland, 2010.

[8] Shareghi, M., Phung, B.T., Naderi, M.S., Blackburn, T.R., Ambikairajah, E., Effects of current and voltage harmonics on distribution transformer losses, International Conference on Condition Monitoring and Diagnosis (CMD), 633-636, 2012.

[9] Soh, T.L.G, Said, D.M., Ahmad, N., Nor, K.M., Salim, F., Experimental study on the impact of harmonics on transformer, IEEE 7th International Power Engineering and Optimization Conference (PEOCO), 686-690, 2013. 